Fanum

Sociológico

\section{Forum Sociológico}

Série II

$22 \mid 2012$

Saúde e multiculturalidade

\title{
A imigração PALOP em Portugal. O caso dos doentes evacuados
}

\section{Maria Adelina Henriques}

\section{(2) OpenEdition \\ 12 Journals}

Edição electrónica

URL: https://journals.openedition.org/sociologico/573

DOI: 10.4000/sociologico. 573

ISSN: 2182-7427

Editora

CICS.NOVA - Centro Interdisciplinar de Ciências Sociais da Universidade Nova de Lisboa

\section{Edição impressa}

Paginação: 53-62

ISSN: 0872-8380

\section{Refêrencia eletrónica}

Maria Adelina Henriques, «A imigração PALOP em Portugal. O caso dos doentes evacuados», Forum Sociológico [Online], 22 | 2012, posto online no dia 26 fevereiro 2013, consultado o 30 março 2022.

URL: http://journals.openedition.org/sociologico/573 ; DOI: https://doi.org/10.4000/sociologico.573

Este documento foi criado de forma automática no dia 30 março 2022

(C) CICS.NOVA 


\title{
A imigração PALOP em Portugal. O caso dos doentes evacuados
}

\author{
Maria Adelina Henriques
}

\section{Introdução}

1 Este artigo tem por base um estudo de caso efetuado para obtenção do grau de Mestre em Demografia e Sociologia da População $^{2}$. Centra-se no tema das migrações, especificamente na imigração oriunda dos PALOP para Portugal, por questões de saúde. $\mathrm{O}$ interesse pelo tema surgiu, naturalmente, do contacto diário com imigrantes PALOP que acompanham as suas crianças em tratamento no Hospital de Dona Estefânia ${ }^{3}$, em Lisboa. Esta proximidade levou a que nos apercebêssemos das dificuldades que enfrentam em Portugal, onde lhes falta quase tudo. Ainda assim, resistem a regressar aos seus países de origem, fazendo crer que desistem da família que por lá ficou. Esta aparente contradição agudizou a nossa curiosidade sobre este fluxo migratório tão específico e que não tem sido objeto de investigação aprofundada em Portugal.

\section{Objetivos do estudo}

2 O objetivo da pesquisa foi, pois, chamar a atenção para este fluxo migratório que vem para Portugal em busca de tratamento médico. Quisemos conhecer todo o processo desde a origem até à origem, isto é, saber como se desenrolam os processos de evacuação, em que condições permanecem os doentes em Portugal, que expetativas têm quanto ao retorno aos seus países de origem.

3 Embora nos últimos anos a imigração em Portugal tenha sido um tema amplamente estudado no meio académico, os enfoques têm privilegiado sobretudo os aspetos económico e cultural. Associando os conceitos de imigração e saúde, procurámos respostas para questões como: "que argumentos justificam o "abandono» da restante família no país de origem em prol de um familiar, (sobre)vivendo em Portugal em condições precárias?", “quem imigra para Portugal por questões de saúde?"; “como se 
desenrolam os processos de evacuação médica?" "quem apoia os doentes evacuados em Portugal?". Sobre estas questões assentam as nossas hipóteses de trabalho:

- A saúde precária nos PALOP é condição suficiente para induzir uma imigração forçada para Portugal;

5 - A debilidade dos programas de cooperação reflete-se nos processos de seleção e no acesso às juntas médicas, induzindo a grandes dificuldades de imigração e posterior integração em Portugal;

6 - A existência de uma forte rede familiar e de solidariedade facilita a sobrevivência destes imigrantes "forçados" em Portugal.

\section{Metodologia}

7 Iniciámos a pesquisa com a procura exaustiva de informação sobre migrações e saúde. No que concerne a produção científica portuguesa, a escassa listagem encontrada denota a incipiente exploração do tema, à data. Com efeito, encontrámos cerca de uma dezena de artigos relacionados com imigração e saúde ${ }^{4}$, todos eles discutindo a saúde dos imigrantes, mas nenhum explorando a questão da saúde como razão da vinda para Portugal. Centram-se nas representações sociais e práticas sobre a saúde e a doença ${ }^{5}$, no acesso aos cuidados de saúde ${ }^{6}$, discutem os imigrantes como grupos de risco $^{7}$ ou estudam-lhes oshábitos e estilos de vida ${ }^{8}$. No campo da produção jornalística, encontrámos artigos que evidenciam as precárias condições em que vivem alguns imigrantes evacuados nas pensões contratadas pelas suas embaixadas ${ }^{9}$. Apoiámo-nos também em literatura cinzenta, produzida pelos seguintes organismos: $\mathrm{INE}^{10}, \mathrm{DGS}^{11}$, $\mathrm{MNE}^{12}, \mathrm{SEF}^{13}$ e ACIDI ${ }^{14}$.

8 A par da procura de informação e com o intuito de explorar caminhos que nos levassem às respostas que pretendíamos alcançar, realizámos também algum trabalho de campo. Entrevistámos vários informadores privilegiados: médicos, enfermeiros e assistentes sociais do HDE, inspetores do SEF, o médico responsável pelos doentes evacuados do HDE, o responsável pela mobilidade de doentes evacuados da DGS, uma enfermeira do gabinete de saúde do $\mathrm{CNAI}^{15}$ de Lisboa, dirigentes de associações de imigrantes, entre outros. De referir também que fizemos várias tentativas para entrevistar funcionários das embaixadas dos PALOP em Lisboa, sobretudo os responsáveis pelos doentes evacuados, as quais resultaram infrutíferas, o que tornou a pesquisa de certa forma menos rica.

9 A estratégia de pesquisa escolhida para este trabalho foi o estudo de caso. Segundo alguns especialistas ${ }^{16}$, este é o método adequado para investigar fenómenos sociais à medida que ocorrem, inseridos no seu contexto natural, sem qualquer interferência do investigador. São particularmente apropriados para pesquisas do tipo "como" e "porquê". No nosso caso, pretendíamos respostas para questões como "porque vieram estes doentes para Portugal", "em que condições vieram", "como vivem em Portugal" e "por que razão não regressam ao seu país de origem". Recorremos à construção de histórias de vida, através da aplicação de entrevistas semidiretivas. Construímos a história de vida de cada um dos inquiridos, desde que, ainda no país de origem, foi diagnosticado um problema de saúde a um filho(a) até à vinda para Portugal.

10 A pesquisa assenta sobre 22 entrevistas feitas a acompanhantes de crianças evacuadas, seguidas na consulta de neurologia do HDE, que foram realizadas entre 2006 e 2007 a 
uma amostra de conveniência. Pretendíamos que a amostra fosse heterogénea em termos de país de origem e sexo, com cerca de 5 representantes de cada PALOP, mas tal não foi possível. Durante a recolha da amostra ${ }^{17}$, a maioria dos utentes evacuados era oriunda sobretudo de São Tomé e Príncipe ${ }^{18}$ e Guiné-Bissau ${ }^{19}$. Nenhum doente evacuado de Moçambique foi à consulta naquele período. De igual forma, quase sempre são as mães das crianças que acompanham os filhos. Daí a predominância de mulheres em detrimento dos homens. Assim, a nossa amostra é composta por ${ }^{19}$ mães e 3 pais, distribuídos da seguinte forma: 9 representantes de STP, 8 de GB, 3 de Cabo Verde ${ }^{20}$ e 2 de Angola. Os 3 representantes masculinos são de CV, GB e STP.

11 Antes de iniciarmos esta pesquisa foram o projeto e o guião de entrevista submetidos à análise da Comissão de Ética do HDE, os quais foram aprovados e autorizados. De igual forma, fomos autorizados a publicar excertos das entrevistas com os inquiridos e informadores privilegiados. No entanto, para não os expormos, não referimos os seus nomes. No caso dos doentes, referiremos apenas o país de origem.

\section{Fluxos migratórios: mais-valias, desafios, teorias}

12 A entrada de imigrantes em Portugal ajuda a rejuvenescer a nossa pirâmide etária, contrariando o duplo envelhecimento no topo e na base ${ }^{21}$. Contribui também para colmatar a escassez de mão de obra em alguns setores do mercado de trabalho, menos procurados pelos autóctones, nomeadamente construção civil no caso dos homens e serviço doméstico no que respeita às mulheres ${ }^{22}$. Funciona ainda como "amortecedor dos ciclos económicos" pela facilidade de flexibilização ${ }^{23}$. Do ponto de vista cultural, os imigrantes oriundos dos quatro cantos do mundo enriquecem o nosso país, transformando-o num "puzzle humano colorido, de inumeráveis cores, línguas, sabores, tradições, culturas, religiões” (AA.VV., 2004: 10). Mas também coloca desafios, requerendo forte capacidade de pensar e bem gerir políticas de integração, ao nível da educação, da saúde, da economia, do emprego, da cultura, da proteção social.

Do ponto de vista do imigrante, a decisão racional de migrar implica também uma aritmética entre ganhos e perdas. Ganhos que se procuram nos países de acolhimento, em termos económicos, profissionais, culturais, de saúde. Perdas pelas ruturas sociais, familiares e culturais, por tudo o que se deixa para trás no país de origem. Tudo isto aliado às naturais dificuldades de integração que podem surgir no país de acolhimento (isolamento, desconhecimento da língua, desenraizamento cultural, saudades dos familiares e do país de origem).

14 São diversas as teorias que explicam a origem dos fluxos migratórios ${ }^{24}$. Dividem-se em teorias micro e teorias macrossociológicas. As primeiras atribuem ao indivíduo o papel principal na decisão de migrar. São perspetivas individualistas, que enfatizam o papel do indivíduo enquanto promotor da decisão de migrar, perseguindo motivações de cariz económico, profissional ou qualificacional. As segundas atribuem a decisão de migrar a condicionantes externos, a dinâmicas que se geram nos contextos dos países de origem e/ou de acolhimento, que influenciam os indivíduos. São perspetivas holísticas. Na realidade elas não são estanques entre si e sob uma decisão ponderada de migrar poderemos encontrar indicadores das duas perspetivas.

15 Não vindo a propósito uma explicitação exaustiva das teorias, focar-nos-emos apenas nas que, em nosso entender, melhor enquadram os fluxos migratórios que este trabalho espelha. São elas as Teorias dos Sistemas Migratórios, das Instituições e das Redes 
Migratórias. Estas teorias alertam para a existência de fatores que se constituem como elementos facilitadores das migrações, mas que não são nem as motivações individuais nem os fatores estruturais exógenos que servem de base à maioria das teorias sobre fluxos migratórios.

A Teoria dos Sistemas Migratórios defende a ideia de que os movimentos das populações resultam de contextos históricos particulares, sendo possível identificar regiões do mundo que são pares entre si e que alimentam fluxos migratórios nos dois sentidos. Apontam para a existência de laços previamente existentes entre os países, que podem ser de índole colonial, comercial, política, militar ou cultural. É o caso dos movimentos migratórios resultantes do recrutamento de mão de obra das ex-colónias para as ex-metrópoles. Castles (2000) considera que os fluxos iniciais são normalmente espoletados por fatores como o serviço militar, os estudos, investimentos, o recrutamento de mão de obra, etc., e que os padrões de deslocação se repetem posteriormente, com a ajuda de quem já se encontra instalado nos países de destino. $O$ caso da imigração PALOP para Portugal é um bom exemplo. Durante a guerra colonial (1961-1974), muitos homens foram recrutados para a guerra, facto que aliado à emigração para o Brasil e Norte da Europa criou no país um déficit de força de trabalho masculina. Foi nesta altura que começaram a chegar até nós africanos ${ }^{25}$, a maioria com poucas qualificações, sobretudo oriundos de $\mathrm{CV}$, que vieram colmatar a escassez de mão de obra no setor da construção civil. Outros, filhos de africanos abastados, vieram estudar em Portugal. E por cá terão ficado alguns. Mas a primeira grande movimentação de africanos para o nosso país deu-se com o regresso de portugueses vindos das ex-colónias, aos quais se juntaram também um número elevado de africanos. Estima-se que tenham entrado em Portugal depois do ${ }^{25}$ de Abril de 1974 cerca de 500 000 homens, entre portugueses retornados e africanos ${ }^{26}$. Esta entrada de africanos "inaugurou" um ciclo de imigração africana para Portugal, que nunca mais parou até aos dias de hoje. Efetivamente, no X recenseamento geral da população, em 1960, não havia ainda registos de população PALOP em Portugal. Em 1981 contabilizaram-se 45 222 indivíduos, número que em 20 anos mais que duplicou, atingindo 101416 em 2001 (Henriques, 2010). Atualmente o efetivo PALOP decresceu ligeiramente, contabilizandose cerca de 95000 indivíduos em 201127. Este decréscimo recente pode explicar-se pelo facto de muitos indivíduos africanos terem adquirido a nacionalidade portuguesa, pela crise económica que tem certamente atraído menos imigrantes a Portugal e por alterações nos processos migratórios em alguns países de origem.

17 A Teoria das Instituições enfatiza o papel de determinadas instituições, tanto na promoção dos fluxos migratórios (entidades empregadoras, "agências de emprego" ${ }^{28}$ ) como no apoio aos mesmos (associações de apoio aos imigrantes).

As Teorias das Redes Migratórias e das Redes Sociais são igualmente importantes para enquadrar os fluxos migratórios em análise, pois enfatizam o papel das redes familiares e de amigos como facilitadores da integração e sedimentação dos fluxos migratórios. Chegam a valorizar mais o papel que parentes e amigos desempenham na partilha de informações e no auxílio aos processos migratórios, do que propriamente o papel das desigualdades entre países pobres e países ricos. 


\section{Os acordos de saúde}

\section{1) Os acordos de cooperação: direitos e deveres}

19 Em 1975 e na sequência das transformações políticas ocorridas em Portugal em Abril de 1974, todas as colónias portuguesas em África se tornaram independentes. Mas Portugal e os PALOP continuaram a manter entre si relações de cooperação e amizade em diversas áreas. Nesse sentido, em 1977, Portugal celebrou acordos de cooperação na área da saúde com $\mathrm{STP}^{29}$ e $\mathrm{CV}^{30}$, que se estenderam posteriormente à $\mathrm{GB}^{31}$, e a Angola ${ }^{32}$ e Moçambique ${ }^{33}$ em 1984. Esses acordos estipularam direitos e obrigações para ambas as partes intervenientes e um plafond anual de doentes autorizados para cada PALOP (Gráfico 1).

Gráfico 1 圈 0 plafond anual de doentes autorizado para cada PALOP

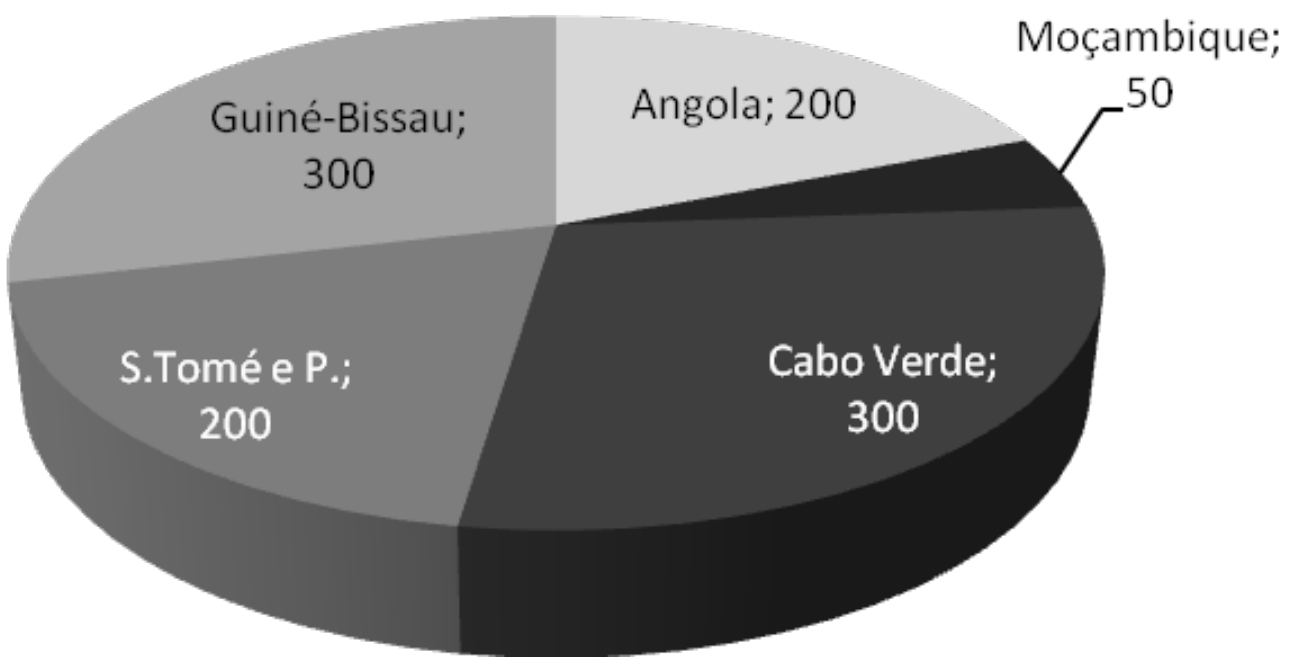

FONTE: DGS Portuguesa

Cada PALOP pode enviar doentes para tratamento em Portugal até esgotar o plafond anual autorizado (300 GB e CV; 200 STP e Angola; 50 Moçambique), desde que esgotadas todas as possibilidades de tratamento no seio do seu próprio país. Mas compromete-se a pagar a viagem de ida e volta aos doentes, a transportá-los do aeroporto ao hospital de destino, a pagar o alojamento e alimentação aos doentes não internados ou depois da alta hospitalar, bem como os medicamentos prescritos em ambulatório e repatriamento em caso de morte. Portugal, por seu lado, compromete-se a prestar tratamento médico em hospitais públicos, em regime de internamento ou hospital de dia, a utilizar meios complementares de diagnóstico e terapêutica quando efetuados em meio hospitalar, a transportar os doentes em ambulância do aeroporto para o hospital quando o quadro clínico o exija.

\section{2) Procedimentos de evacuação}

21 A vinda de doentes ao abrigo destes acordos envolve alguns procedimentos, mais ou menos urgentes, e várias entidades de ambos os países. O Quadro 1 sintetiza o circuito institucionalizado de evacuação atempada de doentes e as entidades envolvidas. 
22 a telefonar para a DGS portuguesa a informar da vinda do doente, e esta por sua vez decide qual o hospital mais adequado para receber o doente e informa-a dessa decisão. No período compreendido entre 1999 e 2010 foram solicitados à DGS portuguesa os pedidos de evacuação constantes no Quadro 2. Como podemos observar, os plafonds anuais autorizados foram quase sempre ultrapassados, exceto nos casos de Angola e Moçambique. CV, STP e GB foram os países que mais recorreram aos serviços médicos portugueses, sobretudo GB (tendo em conta que só temos informação a partir de 2004). Para aferir tal evidência bastará ler os totais em linha. Angola e Moçambique não chegaram a atingir os plafonds autorizados e nos últimos anos quase não têm enviado doentes (Moçambique apenas ultrapassou em 2000 e 2001). Segundo alguns informadores privilegiados, tal facto pode ser explicado pela maior qualidade dos seus próprios serviços de saúde, quando comparados com os dos outros três países em estudo, e pela procura de Cuba e África do Sul para tratamento médico. CV e GB têm enviado mais doentes nos últimos anos. A diferença de cor assinalada no quadro para os últimos 3 anos em análise significa que são dados conseguidos recentemente, que não constavam na pesquisa inicial. Mas as tendências mantêm-se.

\section{Quadro 1 [5: Circuito de evacuação atempada de doentes}

\begin{tabular}{|c|c|c|c|}
\hline Passo $n .^{\circ} 1$ & Passo $n .^{\circ} 2$ & Passo n. ${ }^{\circ} 3$ & Passo n. ${ }^{\circ} 4$ \\
\hline $\begin{array}{l}\text { A junta médica nacional de } \\
\text { cada PALOP elabora um } \\
\text { relatório clínico que } \\
\text { fundamenta a necessidade } \\
\text { de evacuar o doente. }\end{array}$ & $\begin{array}{l}\text { - relatório clínico é } \\
\text { submetido a homologação } \\
\text { do ministro da Saúde de } \\
\text { cada PALOP e o processo é } \\
\text { remetido à embaixada de } \\
\text { cada PALOP em Portugal. }\end{array}$ & $\begin{array}{l}\text { A embaixada remete o } \\
\text { processo à DGS com um } \\
\text { pedido formal para } \\
\text { aceitação do mesmo no } \\
\text { âmbito dos acordos de } \\
\text { cooperação. }\end{array}$ & $\begin{array}{l}\text { A DGS portuguesa aprecia o } \\
\text { pedido, emite parecer } \\
\text { técnico e autoriza a } \\
\text { evacuação do doente, } \\
\text { indicando o hospital público } \\
\text { mais conveniente dada a } \\
\text { patologia em causa. }\end{array}$ \\
\hline Passo n. ${ }^{\circ} 5$ & Passo $n .^{\circ} 6$ & Passo $0^{\circ} 7$ & Passo $n .^{\circ} 8$ \\
\hline $\begin{array}{l}\text { A DGS portuguesa envia } \\
\text { ofício ao departamento der } \\
\text { aestẫa de doentes do } \\
\text { hospital escolhido a solicitar } \\
\text { a marcação da consulta. }\end{array}$ & $\begin{array}{l}\text { O hospital informa a DGS } \\
\text { da data da consulta. }\end{array}$ & $\begin{array}{l}\text { A DGS informa a data da } \\
\text { consulta às seguintes } \\
\text { entidades: embaixada } \\
\text { PALOP, embaixada de } \\
\text { Portugal no PALOP, a qual } \\
\text { comunica ao SEF, no } \\
\text { sentido de facilitar a } \\
\text { obtenção do visto adequado } \\
\text { para o efeito. }\end{array}$ & $\begin{array}{l}\text { A embaixada de cada } \\
\text { PALoP informa o } \\
\text { respectixo, Ministério da } \\
\text { Saúde da marcação da } \\
\text { consulta, para que este } \\
\text { acione os mecanismos } \\
\text { para a deslocação do } \\
\text { doente (pedido de visto, } \\
\text { verbas para pagamento } \\
\text { da viagem, etc.). }\end{array}$ \\
\hline
\end{tabular}

FONTE: DGS Portuguesa 
Quadro 2 臨 N. ${ }^{\circ}$ de pedidos de evacuação para Portugal de 1999 a 2010

\begin{tabular}{|c|c|c|c|c|c|c|c|c|c|c|c|c|c|}
\hline & $9^{19}$ & $0^{20}$ & $0^{20}$ & 02 & $0^{20}$ & $04^{20}$ & $0^{20}$ & $06^{20}$ & $0^{20}$ & $0^{20}$ & $0^{20}$ & $10^{20}$ & $\begin{array}{l}\text { Tot } \\
\text { al }\end{array}$ \\
\hline Ang. & $\begin{array}{r}1 \\
30\end{array}$ & $\begin{array}{r}1 \\
50\end{array}$ & $\begin{array}{r}1 \\
60\end{array}$ & $\begin{array}{l}2 \\
5\end{array}$ & $\begin{array}{l}2 \\
1\end{array}$ & 2 & 0 & $\begin{array}{l}2 \\
6\end{array}$ & $\begin{array}{l}2 \\
8\end{array}$ & 0 & 1 & 0 & $\begin{array}{r}54 \\
2\end{array}$ \\
\hline CV & $\begin{array}{r}3 \\
45\end{array}$ & $\begin{array}{r}3 \\
00\end{array}$ & $\begin{array}{r}3 \\
05\end{array}$ & $\begin{array}{r}3 \\
25\end{array}$ & $\begin{array}{r}2 \\
95\end{array}$ & $\begin{array}{r}2 \\
32\end{array}$ & $\begin{array}{r}2 \\
80\end{array}$ & $\begin{array}{r}2 \\
92\end{array}$ & $\begin{array}{r}2 \\
78\end{array}$ & $\begin{array}{r}3 \\
00\end{array}$ & $\begin{array}{r}3 \\
41\end{array}$ & $\begin{array}{r}3 \\
81\end{array}$ & $\begin{array}{l}36 \\
74\end{array}$ \\
\hline Mopk. & $\begin{array}{l}4 \\
0\end{array}$ & $\begin{array}{l}5 \\
5\end{array}$ & $\begin{array}{l}7 \\
8\end{array}$ & $\begin{array}{l}2 \\
9\end{array}$ & $\begin{array}{l}3 \\
5\end{array}$ & $\begin{array}{l}2 \\
3\end{array}$ & $\begin{array}{l}2 \\
2\end{array}$ & $\begin{array}{l}1 \\
4\end{array}$ & $\begin{array}{l}1 \\
0\end{array}$ & $\begin{array}{l}1 \\
2\end{array}$ & 7 & 6 & $\begin{array}{r}33 \\
1\end{array}$ \\
\hline STP & $\begin{array}{r}2 \\
00\end{array}$ & $\begin{array}{r}3 \\
00\end{array}$ & $\begin{array}{r}2 \\
80\end{array}$ & $\begin{array}{r}3 \\
67\end{array}$ & $\begin{array}{r}2 \\
63\end{array}$ & $\begin{array}{r}2 \\
68\end{array}$ & $\begin{array}{r}1 \\
96\end{array}$ & $\begin{array}{r}1 \\
78\end{array}$ & $\begin{array}{r}1 \\
72\end{array}$ & $\begin{array}{r}2 \\
10\end{array}$ & $\begin{array}{r}2 \\
26\end{array}$ & $\begin{array}{r}1 \\
94\end{array}$ & $\begin{array}{l}28 \\
54\end{array}$ \\
\hline GB & 0 & 0 & 0 & 0 & 0 & $\begin{array}{r}1 \\
57\end{array}$ & $\begin{array}{r}2 \\
45\end{array}$ & $\begin{array}{r}4 \\
88\end{array}$ & $\begin{array}{r}5 \\
07\end{array}$ & $\begin{array}{r}7 \\
19\end{array}$ & $\begin{array}{r}7 \\
45\end{array}$ & $\begin{array}{r}4 \\
03\end{array}$ & $\begin{array}{l}32 \\
64\end{array}$ \\
\hline Total & $\begin{array}{r}7 \\
15\end{array}$ & $\begin{array}{r}8 \\
05\end{array}$ & $\begin{array}{r}8 \\
23\end{array}$ & $\begin{array}{r}7 \\
46\end{array}$ & $\begin{array}{r}6 \\
14\end{array}$ & $\begin{array}{r}6 \\
82\end{array}$ & $\begin{array}{r}7 \\
43\end{array}$ & $\begin{array}{r}9 \\
98\end{array}$ & $\begin{array}{r}9 \\
95\end{array}$ & $\begin{array}{r}1 \\
241\end{array}$ & $\begin{array}{r}1 \\
320\end{array}$ & $\begin{array}{r}9 \\
84\end{array}$ & $\begin{array}{r}10 \\
666\end{array}$ \\
\hline
\end{tabular}

FONTE: DGS Portuguesa

\section{A vinda para Portugal: triagem, tempos de espera e financiamento}

\section{1) A seleção dos doentes a evacuar}

No país de origem a seleção dos candidatos a junta médica é um processo que obedece a fatores de natureza diversa e que raramente é fácil. A geografia do país é por si só fator discriminatório, uma vez que quem habita nas regiões periféricas tem muitas dificuldades em chegar aos centros de saúde. As estradas e os meios de transporte deficientes, aliados aos fracos recursos económicos de quem mora longe dos centros urbanos, são fatores de exclusão "natural". Os postos médicos situados longe dos centros urbanos raramente têm meios de tratamento ou de transporte dos doentes aos hospitais. Existem poucas ambulâncias e pouco dinheiro para combustível e manutenção. Quem vive nos centros urbanos, ou próximo destes, tem a vida mais facilitada em termos de acesso à saúde. Mesmo assim, segundo os relatos, nos hospitais falta por vezes quase tudo. Os meios complementares de diagnóstico são raros ou nem existem, daí a necessidade de se recorrer à evacuação dos doentes para os hospitais portugueses. O tradicional recurso aos curandeiros também condiciona a ida aos centros de saúde. Fora dos centros urbanos, esta é quase sempre a primeira escolha, pelo que em muitas ocasiões recorrem ao centro de saúde numa fase avançada da doença, muitas vezes tarde de mais. Com frequência colocam as suas vidas nas mãos de entidades como o ira $\tilde{a}^{34}$ ou no Poilão $0^{35}$, no caso da GB, a quem prestam culto, à volta dos quais organizam rituais e pedem pela sua saúde. Foi referido por alguns informadores privilegiados, relativamente à GB, a existência de uma espécie de "comércio" de juntas médicas em que o médico propõe alguém a junta médica mediante um pagamento, $\mathrm{o}$ que põe em causa a veracidade e transparência dos processos de triagem. $O$ responsável pelos doentes evacuados do HDE referiu-nos que por vezes chegam ao hospital casos que não justificam a vinda para Portugal. São doentes que não têm cura, com paralisias cerebrais profundas, ou doentes que não justificam a evacuação, com anemias, por exemplo, o que demonstra que nem sempre a triagem é bem conseguida. 


\section{2) 0 tempo de espera no país de origem}

Logo que é diagnosticada uma patologia cujos meios de tratamento não existam no país de origem, inicia-se o processo de evacuação, com a proposta do doente a junta médica. Mas, segundo os relatos, desde este momento até à chegada a Portugal travam-se verdadeiras batalhas: com o Ministério da Saúde, com o Ministério das Finanças, com as embaixadas. Por isso, há que recorrer a estratégias várias para transpor os obstáculos com que se defrontam durante o processo. Acusam o Sistema Nacional de Saúde dos seus países de funcionar de forma pouco eficiente e denunciam a necessidade de ter contactos bem posicionados no circuito de evacuação para facilitar a vinda para Portugal. Os excertos seguintes são reveladores da importância desses contactos:

“(...) eu era militar, mas cortava o cabelo ao embaixador e a políticos (...) e essa influência fez com que eu viesse mais depressa (...)" (STP).

“(...) o pai do Pedro, que é militar, falou com um amigo que trabalha no gabinete do presidente (...) (GB)

“(..) não demorei muito a vir porque o meu marido, que trabalha nas finanças, tratou de tudo (...)" (GB)

Quando os capitais social e económico não abundam, há que recorrer a outras estratégias. Nesse sentido, há os que se "armam" de coragem e confrontam o poder do Estado, tentando sensibilizar, apelando ao sentimento:

“(...) fui falar com o ministro da Saúde... disse que estava com medo que o meu filho morresse, tirei a roupa ao José, mostrei o problema do menino e todo o mundo ficou com pena (...)" (STP);

“(...) fui falar com o primeiro-ministro e disse que não me ajudavam porque eu era pobre, que se fosse filho de rico já tinha sido evacuado (...)” (STP).

Gráfico 2 迤 Tempo de espera pela junta médica, no país de origem

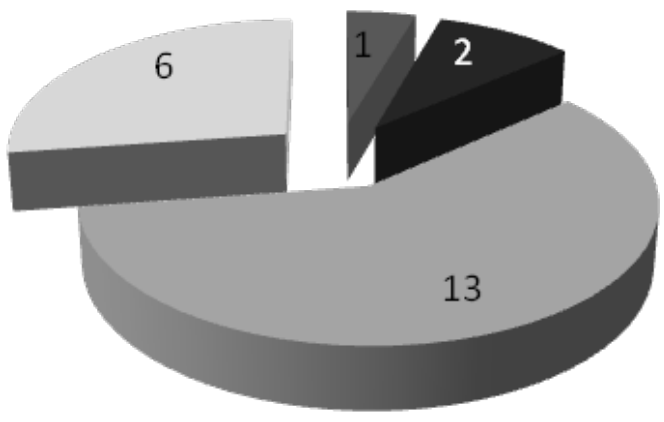

FONTE: Henriques, 2010

Mais de 5 anos de espera

Entre 3 e 5 anos de espera

Entre 1 e 3 anos de espera

Menos de 1 ano de espera

Como o Gráfico 2 evidencia, dos 22 inquiridos, 13 estiveram entre 1 e 3 anos à espera de vir para Portugal, 2 esperaram entre 3 e 5 anos, e 1 esperou mais do que 5 anos pela junta médica, o que ilustra bem o quão moroso pode ser um processo de evacuação. Curiosamente, as entrevistas revelaram-nos que os 6 entrevistados que demoraram menos de 1 ano para vir para Portugal tinham contactos bem posicionados no circuito de evacuação ou tiveram quem lhes pagasse a viagem de imediato, sem recorrer ao Ministério das Finanças. A burocracia e inércia dos ministérios e embaixadas, associadas aos processos de triagem deficientes, induzem a longos meses e anos de espera, que se traduzem com frequência na evolução das doenças para estádios irreversíveis e que poderiam ser evitados se os doentes chegassem mais rapidamente a 
Portugal. "A manter-se a situação atual (...) mais não nos resta do que continuar a oferecer a muitos meninos PALOP cuidados paliativos diferenciados", afirma a diretora da consulta externa de neurologia do HDE, em entrevista.

\section{2) 0 financiamento da viagem}

Outro dos obstáculos que se colocam aos doentes que esperam a evacuação médica é o pagamento da viagem. Esta deveria ser sempre paga pelo Ministério das Finanças do país de origem, conforme estipulado nos acordos celebrados, mas, muitas vezes, os longos meses de espera e o descrédito nos serviços públicos determinam a venda dos parcos haveres de cada um, para financiar a viagem e acelerar o processo da vinda. Recorre-se muito à família e à solidariedade alheia, que se mobiliza através da comunicação social, das escolas e da igreja. Como ilustram os seguintes depoimentos:

“(...) não tinha dinheiro para a viagem, pedi a um tio que está na Noruega e ele é que pagou a viagem (...)" (GB);

“(...) após inúmeras idas em vão às finanças para levantar o dinheiro, cheguei à conclusão que se não queria perder outro filho tinha que agir rápido. Conversei com o meu irmão e decidi vender a canoa de pesca do meu marido, o motor da pesca e a televisão (...)" (STP);

“(...) o Sr. Martinho que trabalha no hospital disse que o meu visto saiu e Frei Michael é que pagou a viagem (...)" (GB);

“(...) para conseguir dinheiro para a viagem fui falar com a televisão... uma escola organizou-se, fez um peditório e consegui dinheiro para a viagem (...)” (GB);

“(...) fui para a rádio Voz de Cabo Verde pedir ajuda... eles se organizaram, iniciaram uma campanha... as pessoas aderiram logo e ajudaram com dinheiro (...)" (CV).

Os Gráficos 3 e 4 mostram que as embaixadas pagaram a viagem na totalidade apenas a 7 inquiridos e 50\% do valor a 1 inquirido. Os restantes 14 tiveram de apelar à comunicação social, à igreja, vender os seus haveres ou recorrer à família. A solução está maioritariamente na família, como mostra o Gráfico 4.

Gráfico 3 臨 $\mathrm{N} .^{\circ}$ de viagens pagas por cada embaixada

\section{Guiné-Bissau; 1}

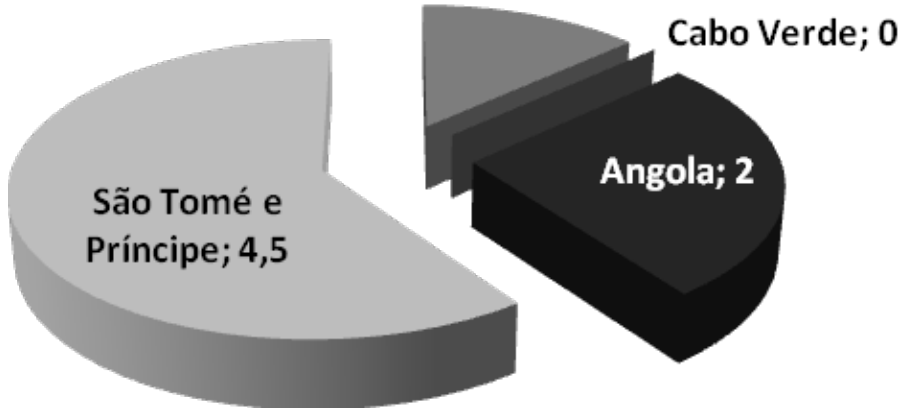

Guiné-Bissau

- Cabo Verde

Angola

São Tomé e Príncipe

FONTE: Henriques, 2010 


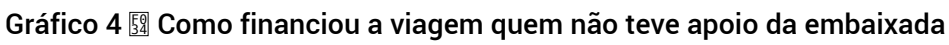

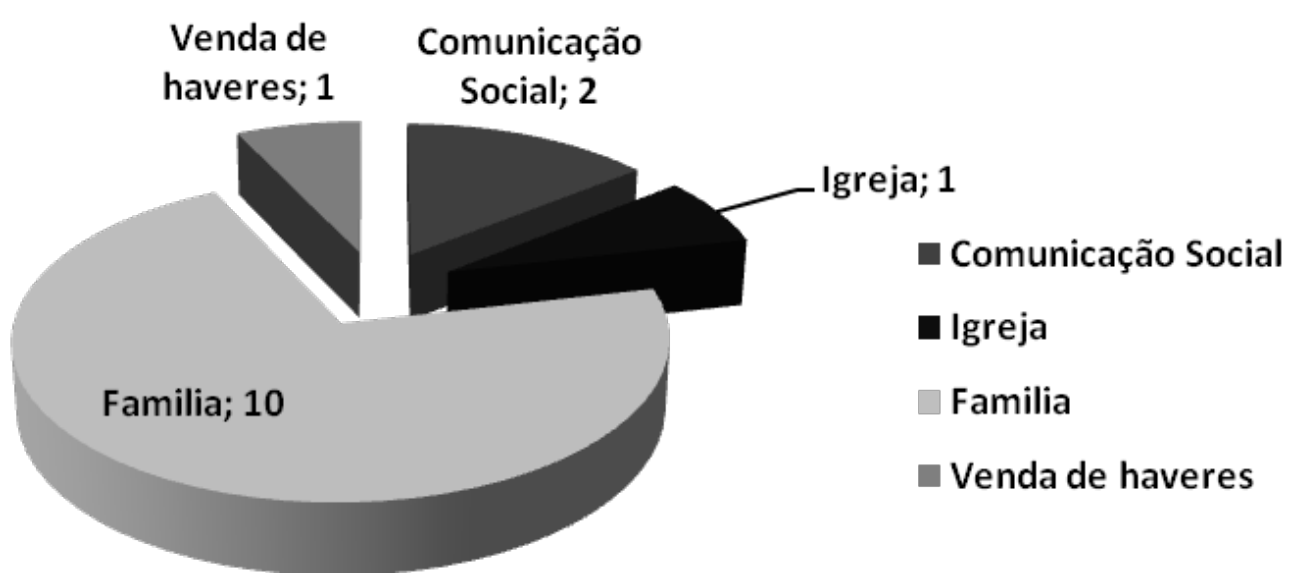

FONTE: Henriques, 2010

\section{(Sobre)vivência em Portugal - alojamento e alimentação}

Garantir o alojamento e a alimentação aos doentes evacuados faz igualmente parte das obrigações a que os PALOP ficaram sujeitos quando celebraram os acordos. No entanto, nem sempre é o que acontece. Relativamente à nossa amostra, as embaixadas só garantiram alojamento e alimentação a 3 dos 22 inquiridos, e, segundo os relatos, em condições bastante precárias. Queixam-se das fracas condições de habitabilidade das pensões onde foram alojados e de uma alimentação igualmente deficiente. Eis um depoimento elucidativo:

“(...) eu vivia numa pensão, eu nem gosto de falar... a embaixada dava 50 紫 por mês para a comida, eu tinha que cozinhar no quarto... então, panelas lá mesmo, pratos lá mesmo no chão... tinha que lavar pratos na casa de banho, cozinhar com água da casa de banho... para ir para a cama tinha que saltar panela... se deixava panela aberta logo entrava barata (...)" (STP).

\section{Regresso ao país de origem}

31 Questionados sobre o regresso ao país de origem, 19 inquiridos foram perentórios em afirmar não querer regressar (Gráfico 5). Invocaram razões que se prendem com a continuidade do tratamento dos seus filhos e com o facto de não terem trabalho no país de origem. Frases como "lá não há tratamento", "lá não há tratamento nem trabalho" ou "tenho cá a família toda" representam a opinião da maioria dos que optam por não regressar (Quadro 6). 


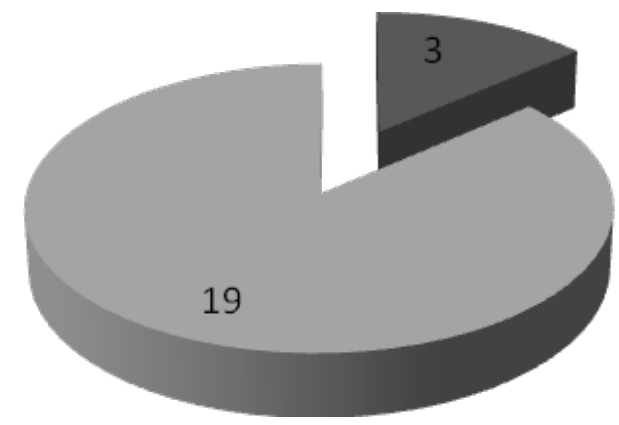

Querem voltar

Querem ficar em Portugal definitivamente

FONTE: Henriques, 2010

Gráfico 6 通 Argumentos para não regressar ao país de origem

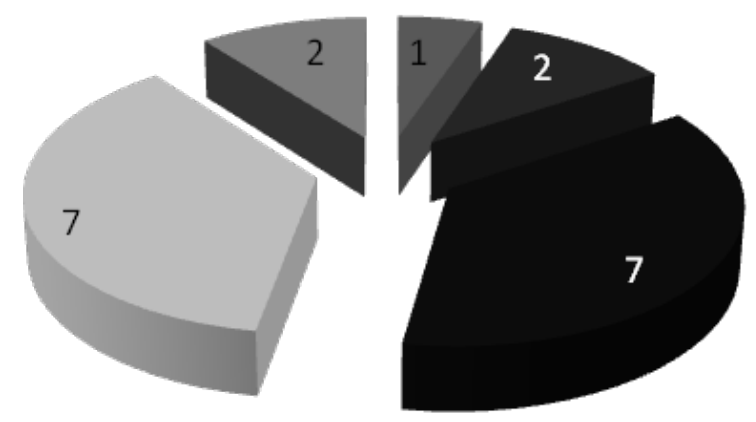

Vim de férias para ficar

Não há tratamento nem trabalho

Não há trabalho nem ordenado

Não há tratamento

Tenho cá a família toda

FONTE: Henriques, 2010

Conhecendo a morosidade e os constrangimentos destes processos de evacuação, é compreensível que os inquiridos não queiram sujeitar-se a passar por tudo de novo, caso necessitem de avaliações médicas posteriores. Apesar das muitas dificuldades por que passam em Portugal, sobem quase sempre na hierarquia social, relativamente à vida que levavam no país de origem, onde a maioria trabalhava no campo, sem salário. A existência das diásporas provenientes dos PALOP, já fortemente integradas e enraizadas em Portugal e que se assumem como facilitadoras da integração dos que acabam de chegar, bem como a facilidade de reagrupamento familiar que a actual Lei de Estrangeiros prevê (Lei 23/2007 de 4 de Julho posteriormente alterada pela Lei 29/2012 de 9 de Agosto), constituem-se como fortes argumentos para o não regresso ao país de origem.

\section{Considerações finais}

Chegados a este ponto permitimo-nos tecer algumas considerações, alertando, no entanto, para o carácter exploratório da pesquisa, que assentou sobre um estudo de caso, pelo que todas as ilações que dele extraímos se reportam única e exclusivamente a ele, não podendo ser generalizadas para o universo de todos os doentes evacuados provenientes dos PALOP.

Depreendemos facilmente que os processos de evacuação em causa foram processos morosos e sofridos por parte dos que deles necessitaram. Os depoimentos denunciam 
deficientes e pouco claros processos de triagem, que nem sempre enviam para Portugal as pessoas que mais precisam. Denunciam também o incumprimento, por parte dos países de origem, das obrigações a que se comprometeram pela assinatura dos acordos de cooperação há mais de 30 anos. Este incumprimento induz a situações de precariedade, só amenizadas pelo apoio de familiares, amigos e, por vezes, até de desconhecidos. "Desabafos" de membros de associações que apoiam estes doentes referem que algumas embaixadas nem sabem quantos doentes têm em Portugal, nem enviam representantes para os visitar nas casas que por caridade os acolhem. Parecem nutrir pelos doentes um desinteresse total. Esta falta de apoio potencia situações de grande vulnerabilidade. Para sobreviver, os inquiridos sujeitam-se a patrões pouco escrupulosos que se aproveitam do seu isolamento e desconhecimento de direitos para lhes extorquir a sua força de trabalho a troco de quase nada. Alimentam o sector informal da economia, moram frequentemente em anexos com poucas condições de habitabilidade, sobrevivem sem direitos. Do ponto de vista da saúde, a falta de apoio a estes indivíduos que vieram para Portugal tratar as suas patologias pode resultar num agravamento dessas patologias ou até induzir a outras, uma vez que para conseguirem auto-sustentar-se negligenciam as consultas no hospital, a compra de medicamentos, chegando a abandonar definitivamente os tratamentos. Frequentemente deixam os filhos em casa, entregues a si próprios, na rua, ou com qualquer um que se ofereça, para poderem ir ganhar o seu sustento. Ainda assim, a maioria prefere ficar em Portugal do que regressar ao seu país. As "batalhas" que enfrentaram, as ruturas familiares e culturais a que se sujeitaram foram demasiado penosas para que se arrisquem a passar por tudo outra vez se tiverem de voltar para avaliações médicas. A falta de tratamento médico e de medicamentos nos seus países, aliados ao facto de não haver trabalho, levam a que escolham viver definitivamente em Portugal, apesar das saudades dos que por lá ficaram. Acreditam na possibilidade do reagrupamento familiar permitido pela Lei de Estrangeiros, para mandar vir para Portugal a família que ficou do lado de lá do oceano. Sonham com um futuro melhor para os seus filhos.

Ao longo da pesquisa sentimos também a forte presença das redes familiares. Constatámos que os laços de solidariedade entre os africanos cimentam um conceito de família que extravasa largamente os laços de sangue, o conceito de família europeu. Efetivamente, as redes sociais e familiares jogam um papel fundamental na vida destes imigrantes. Em situações de carência torna-se fundamental esse apoio. São eles o suporte económico, psicológico e cultural destas pessoas, pois "reduzem os custos e os riscos da imigração" (Kelly, 2000: 53). Os que não têm familiares em Portugal podem mesmo, em casos extremos, tornar-se vítimas do isolamento e engrossar o número de imigrantes com problemas de stresse saúde mental.

“(...) a rutura das relações sociais e familiares (...) gera uma redução do suporte social e emocional dos indivíduos. A ausência de estrutura familiar e de outros mecanismos microssociais de apoio à estabilidade individual (...) pode aumentar a vulnerabilidade e perpetuar a exposição a fatores de risco e favorecer práticas prejudiciais à saúde (...) (álcool, tabagismo, outras drogas)." (Dias, 2007: 19).

Também as associações de defesa dos imigrantes desempenham um papel fundamental, não só em termos económicos, mas constituindo-se como "estruturas vitais de processos de socialização, de reforço de laços culturais comuns, de afirmação identitária, de solidariedades e de práticas de entreajuda, desempenhando um papel fundamental na vida dos migrantes face a situações de isolamento e, frequentemente, de adversidades decorrentes do percurso migratório" (Horta, 2010: 11). 


\section{Algum caminho percorrido, muito caminho a percorrer}

O problema que este estudo retrata já foi identificado e sinalizado como urgente por diversas entidades. É disso exemplo a criação do $\mathrm{PADE}^{36}$, resultante de uma parceria entre o ACIDI e o ISS ${ }^{37}$, no âmbito do segundo Plano de Integração de Imigrantes (PII) e que foi concebido para, tal como o nome sugere, dar apoio aos doentes estrangeiros, nomeadamente os oriundos dos PALOP, garantindo-lhes alojamento, alimentação, apoio psicológico e social. Para tal foram criadas casas de acolhimento cujo objetivo é acompanhar os doentes desde o país de origem, durante o tratamento em Portugal, e no regresso ao país de origem, no caso de poderem regressar. Os que não podem regressar, pelo facto de terem doenças que obstam ao regresso ao seu país de origem, são encaminhados para o SEF, no sentido de obterem uma autorização de residência nos termos da alínea g) do art. 122 da Lei 23/2007. Em meados de 2008, quando finalizámos a pesquisa, foi inaugurada a primeira casa de acolhimento no âmbito deste projeto. Actualmente verificamos com agrado que já existem sete, o que demonstra que, se por um lado continuam a existir doentes necessitados, também existe consciencialização do problema e vontade para procurar soluções.

Em relação às políticas de cooperação, muito há a fazer. A atualização dos acordos de cooperação é urgente. Melhor do que evacuar doentes para Portugal será tratá-los no seu país de origem, sem os constrangimentos e custos sociais a que se sujeitam vindo para Portugal. Já para não falar dos custos monetários para Portugal, não só em termos do tratamento dos doentes quando chegam mas posteriormente com a integração em Portugal. O reforço de equipas médicas para se deslocarem aos PALOP, a formação de profissionais de saúde nos PALOP, a dotação dos hospitais locais com mais e melhores equipamentos, a aposta na telemedicina e na garantia de processos de triagem mais claros e mais eficazes constituir-se-iam como um primeiro grande passo para minorar o problema em análise.

Em termos académicos, e sem ponderar a exequibilidade do projeto, seria interessante fazer um balanço dos cerca de 40 anos de cooperação com os PALOP, no âmbito da saúde, fazendo um levantamento exaustivo, a nível nacional, de todos os doentes evacuados que vieram para Portugal desde a celebração dos acordos e dos custos sociais e económicos a eles associados.

Outro tema interessante seria um inquérito de opinião, aplicado a nível nacional a todos os profissionais de saúde dos hospitais públicos, sobre a questão dos doentes evacuados e dos acordos de saúde, com recolha de propostas para solucionar a questão da desatualização dos acordos de saúde, para depois de sistematizadas as apresentar na Assembleia da República. 


\section{BIBLIOGRAFIA}

AA.VV. (2004), Actas do I Congresso de Imigração em Portugal - Diversidade, Cidadania, Integração, Lisboa, ACIME.

BÄCKSTRÖM, B. (2007), Saúde e imigrantes: as representações e as práticas sobre a saúde e a doença na comunidade cabo-verdiana em Lisboa, Tese de doutoramento, Lisboa.

BAGANHA, M. e P. Gois (1998/1999), “Migrações Internacionais de e para Portugal: o que fazemos e para onde vamos?” in Revista Crítica de Ciências Sociais, Coimbra, n.ำ52/53, pp. 229-280.

BAGANHA, M. (2005), "Política de imigração: a regulação dos fluxos", Revista Crítica de Ciências Sociais, n. ${ }^{\circ} 73$, Coimbra, pp. 29-44.

CARVALHO, L. (2004), Impacto e reflexos do trabalho imigrante nas empresas portuguesas - uma visão qualitativa, Lisboa: ACIME/OI.

CASTLES, S. (2000), "International Migration at the Beginning of the Twenty-First Century: Global Trends and Issues”, International Social Sciences Journal, UNESCO, no. 165.

CASTLES, S. (2005), Globalização, Transnacionalismo e novos fluxos migratórios. Dos trabalhadores convidados às migrações globais, Oeiras, Celta.

CASTLES, S. e M. J. Miller, (1998), The age of migration: international population mouvements in The modern world, Londres, Macmillan.

DIAS, S. e A. Gonçalves (2007), "Migrações e Saúde” in Imigração e Saúde, Migrações, N. 1, Lisboa, OI.

ESTEVES, M.a do Céu (org.) (1991), Portugal, país de imigração, Lisboa, Instituto de Estudos para o desenvolvimento, Caderno 22.

FERREIRA, E., H. Rato et al. (2004), Viagens de Ulisses. Efeitos da imigração na economia portuguesa, Lisboa, ACIME, OI.

FIDEL, R. (1992), “The case study method: a case study” in J. Glazier e R. Powell, Qualitative Research in information management, Englewood: Libraries Unlimited.

FIGUEIREDO, J. (2005), Fluxos migratórios e cooperação para o desenvolvimento - realidades compatíveis no contexto europeu?, Lisboa, ACIME.

GONÇALVES, A. (2003), “Acesso aos cuidados de saúde de comunidades migrantes: problemas e perspectivas de Intervenção” in Revista Portuguesa de Saúde Pública, N.ㄹ 21, Lisboa, Escola Nacional de Saúde Pública e Universidade Nova de Lisboa.

GOUVEIA, J. (1998), Acordos de Cooperação entre Portugal e os Estados Africanos Lusófonos, Coimbra: Cooperação Portuguesa.

HARTLEY, J. (1994), “Case Studies in organizational Research” in C. Cassel e G. Symon (orgs.), Qualitative methods in organizational research: a practical guide, Londres, Sage.

HENRIQUES, M.adelina (2010), Argumentos para uma viagem sem regresso. A imigração Palop por via da saúde: um estudo de caso, Lisboa, OI, Colecção Teses, N. 32 .

HORTA, A. (2010), “Introdução” in Associativismo imigrante, Revista Migrações, N. 6, Lisboa, OI.

KELLY, C. (2000), "Demography and International Migration”, in C. Brettel e J. Hollifield (Org.), Migration Theory - Talking across Disciplines, Londres, Routledge. 
LECHNER, E. (2007), “Imigração e saúde mental” in Imigração e saúde, Revista Migrações, N. 1, Lisboa, OI.

MACHADO, F. e A. Matias (2006), Bibliografia sobre imigração e minorias étnicas em Portugal 2000-2006, Lisboa, FCG.

MATOS, M. et al. (2005), Aventura Social, etnicidade e risco. Prevenção primária do VIH em adolescentes de comunidades migrantes, Lisboa, IHMT.

PEIXOTO, J. (2004), “As teorias explícitas das migrações: teorias micro e macro sociológicas I” in Socius Working Papersn. ${ }^{-}$11, pp. 3-32.

PETRAS, E. M. (1981), “The global labor market in the modern world-economy”, in M. M. Kritz et al. (Ed.), Global Trends in Migration - Theory and Research on International Population Movements, Nova Iorque, Center for Migration Studies, pp.

44-63.

PORTES, A. (1981), "Modes of structural incorporation and present theories of labor immigration", in M. M. Kritz et al. (Ed.), Global Trends in Migration - Theory and Research on International Population Movements, Nova Iorque, Center for Migration Studies, pp. 279-297.

PORTES, A. (1999), Migrações Internacionais. Origens, Tipos e Modos de Incorporação, Oeiras, Celta.

ROSA, M. João V. (1993), "O desafio social do envelhecimento demográfico” in Análise Social, Vol. XXVIII, N.1ㄴ 122 , pp 679-689.

ROSA, M. ' João V. et al. (2004), Contributos dos imigrantes na demografia portuguesa - o papel das populações de nacionalidade estrangeira, Lisboa, OI.

Jornal Público, de 30/11/2005.

Relatórios de Imigração, Fronteiras e Asilo dos anos 2008, 2009, 2010, 2011.

\section{NOTAS}

1. Países Africanos de Língua Oficial Portuguesa.

2. ISCTE.

3. Doravante designado apenas por HDE.

4. Ver levantamento bibliográfico feito por Fernando Luís Machado e Ana Raquel Matias, sobre imigração e minorias étnicas em Portugal 2000 - 2006, de onde resultaram apenas sete artigos relacionados com imigração e saúde.

5. Ver Bäckström, 2007.

6. Ver Gonçalves, 2003.

7. Dias e Gonçalves, 2007.

8. Ver Matos, Gonçalves e Gaspar, 2005.

9. Ver o jornal Público de 30/11/2005.

10. Instituto Nacional de Estatística.

11. Direção-Geral da Saúde.

12. Ministério dos Negócios Estrangeiros.

13. Serviço de Estrangeiros e Fronteiras.

14. Alto Comissariado para a Imigração e Diálogo Intercultural.

15. Centro Nacional de Apoio ao Imigrante.

16. Ver a propósito Fidel, 1992; Hartley, 1994. 
17. Que acontecia à medida que os doentes evacuados apareciam na consulta, em 2006.

18. Doravante designado apenas por STP.

19. Doravante designado apenas por GB.

20. Doravante designado apenas por CV.

21. Ver Rosa, 1993.

22. Ver Carvalho, 2004.

23. Ver Ferreira, Rato e Mortágua, 2004.

24. Ver, para maior desenvolvimento, Peixoto, 2004; Castles, 2005; Castles e Miller, 1998; Petras, 1981; Portes, 1981; Baganha, 1998/1999; Portes 1999; Kelly, 2000; e Figueiredo, 2005.

25. À data ainda portugueses.

26. Desse número, cerca de 205000 eram africanos (ou deveremos dizer portugueses?) - ver, a propósito, Baganha, 2005.

27. Relatório de Imigração Fronteiras e Asilo, 2011.

28. Grupos que fomentam a imigração ilegal.

29. Decreto N. $25 / 77$ de 3 de Março.

30. Decreto N. $.24 / 77$ de 3 de Março.

31. Decreto N.. 44/92 de 6 de Outubro.

32. Decreto N. $.39 / 84$ de 13 de Julho.

33. Decreto N. 0 35/84 de 12 de Julho.

34. Figura das religiões tradicionais africanas que representa o espírito de um antepassado.

35. Árvore sagrada onde se recolhe a alma/espírito de alguém falecido.

36. Programa de Apoio a Doentes Estrangeiros.

37. Instituto de Segurança Social.

\section{RESUMOS}

Todos os dias chegam ao nosso país pessoas oriundas dos PALOP $^{1}$ que vêm tratar a sua saúde nos nossos hospitais. Umas chegam ao abrigo dos acordos de saúde celebrados com Portugal, outras vêm com um qualquer visto de estada temporária. Mas vêm, porque no seu país não existe tratamento para os seus males! Por isso nos deparamos com uma grande diversidade cultural nos nossos hospitais, reforçada pelo peso dos imigrantes provenientes desses países em Portugal.

Subjacente à vinda de muitos destes doentes, estão anos de "batalhas", de sofrimento, enquanto aguardam a decisão do Ministério da Saúde do seu país quanto ao pedido de junta médica, ou aguardam as verbas do Ministério das Finanças para pagamento da viagem para Portugal ou esperam por um visto. Também os processos de triagem nos países de origem apontam para processos de seleção pouco claros e ineficazes.

Já em Portugal, a falta de apoio das suas embaixadas, associada a fatores como o desconhecimento da língua, o desenraizamento cultural, entre outros, leva a que muitas destas pessoas vivam com grandes dificuldades. Apesar dos problemas com que estes doentes (sobre)vivem em Portugal, muitos não querem regressar ao país de origem. A dificuldade em obter tratamento médico e medicamentos é a razão mais apontada para não regressar.

Everyday a number of Portuguese-speaking African immigrants arrive to Portugal looking for health care in portuguese hospitals. Some arrive in the framework of the health protocols signed with Portugal, whilst others arrive with a temporary visa. These immigrants come to Portugal 
since no adequate health care exists in their countries of origin. This movement adds to the cultural diversity existing nowadays in portuguese hospitals.

Hidden behind the arrival of many of these patients are years of struggle and suffering. These immigrants must wait for a decision of the health ministry of their countries concerning a request for a medical committee (necessary to determine the evacuation needs); must wait for financial support from their finance ministry, in order to pay the travel to Portugal; and must wait for a visa. Also the selection process in their countries of origin sometimes seems insufficiently transparent and efficient.

In Portugal, the lack of support from their embassies, coupled with factors such as poor linguistic skills and cultural uprooting, explain why many of these patients and their families undergo significant hardship. However, despite these difficulties, many are not willing to return to their countries of origin. The difficulties of getting medical support and adequate medicine are the most cited reasons for non return.

\section{ÍNDICE}

Palavras-chave: imigração, saúde, Portugal, PALOP, acordos de cooperação, doentes evacuados Keywords: immigration, health, Portugal, PALOP, health protocols, evacuated patients

\section{AUTOR}

\section{MARIA ADELINA HENRIQUES}

Licenciada em Sociologia - ISCTE-IUL; Mestre em Demografia e Sociologia da População - ISCTEIUL; Pós-graduada em Avaliação e Desenvolvimento Organizacional na Administração Pública ISCTE-IUL (dinah2006@gmail.com) 